\title{
Application of the Beauveria bassiana Strain for the Enantioselective Oxidation of the Diethyl 1-Hydroxy-1-Phenylmethanephosphonate
}

\author{
Ewa Żymańczyk-Duda • Małgorzata Brzezińska-Rodak • \\ Magdalena Klimek-Ochab • Barbara Lejczak
}

Received: 7 October 2010/Accepted: 29 November 2010/Published online: 15 December 2010

(C) The Author(s) 2010. This article is published with open access at Springerlink.com

\begin{abstract}
Biotransformation of diethyl 1-hydroxy-1-phenylmethanephosphonate using fungi Beauveria bassiana allowed resolving the racemic mixture of the substrate and due to the biocatalyst and reaction conditions modifications, leading to desired optical isomer.
\end{abstract}

\section{Introduction}

"Efficiency" and "selectivity" are two key words that better outline the outstanding of biocatalysts performance. Chirality is, in the most cases, the most important factor in the safety and efficacy of many drug products [1]. Usually, only one enantiomer is responsible for the desired activity, whereas its counterpart can be inactive, be an antagonist of the active one or posses other desirable activity or is no active at all. Biocatalysts are applied usually, when chemical synthesis fails either when products of desired chirality are required or because of the environmental purposes [9, 14, 18, 20]. Microbial biocatalysts demonstrated wide variations of activities, though it justified dynamic development of the biotransformation field of science [7, 13]. Phosphonates are compounds containing direct $\mathrm{P}-\mathrm{C}$ bond. Among them are molecules with one or two stereogenic centers, their biological activities range from the medicine to agriculture and strongly dependent on their absolute configuration. They affect the amino acids metabolism influencing the activity of the enzymes

E. Żymańczyk-Duda ( $₫) \cdot$ M. Brzezińska-Rodak ·

M. Klimek-Ochab · Barbara Lejczak

Department of Bioorganic Chemistry, Faculty of Chemistry,

Wrocław University of Technology, Wybrzeże Wyspiańskiego

27, 50-370 Wrocław, Poland

e-mail: ewa.zymanczyk-duda@pwr.wroc.pl involved in it via structural analogy to the particular carboxylic acids or by the transition state imitation (during the enzymatic peptide bond hydrolysis) [2, 4-6, 12]. They act as antibacterials, antivirals, neuromodulators, chelating agents in bone diseases or herbicides, and also they can serve as chiral building blocks in combinatorial chemistry [2, 4-6, 12]. Biocatalyzed synthesis of chiral, organophosphorus compounds is still not fully explored, although during last decade purified enzymes and whole microbial cells were successfully used for the synthesis of structurally different, optically pure phosphonate derivatives $[3,8,10$, $11,15,19,21,22,24]$. Here, we report effective and simple strategy, which allowed obtaining non-racemic, diethyl 1-hydroxy-1-phenylmethanephosphonate in both optical forms, with the yield of $20 \%$ (resolution of the racemic mixtures is under kinetic control) (Fig. 1). This compound represents a structure of possible application as a chiral building block or chelating agent and as a potential enzyme inhibitor.

\section{Materials and Methods}

Substrate Synthesis

Substrate was synthesized according to the standard procedure by the addition of equimolar ratio of diethylphosphite and KF to benzaldehyde at the presence of catalytic amount of anhydrous $\mathrm{Al}_{2} \mathrm{O}_{3}$ (stirring, room temperature, $24 \mathrm{~h}$ ) [17].

Microorganism Cultivation

Beauveria bassiana strain (DSM 875) was purchased from German Collection of Microorganisms and Cell Cultures. 


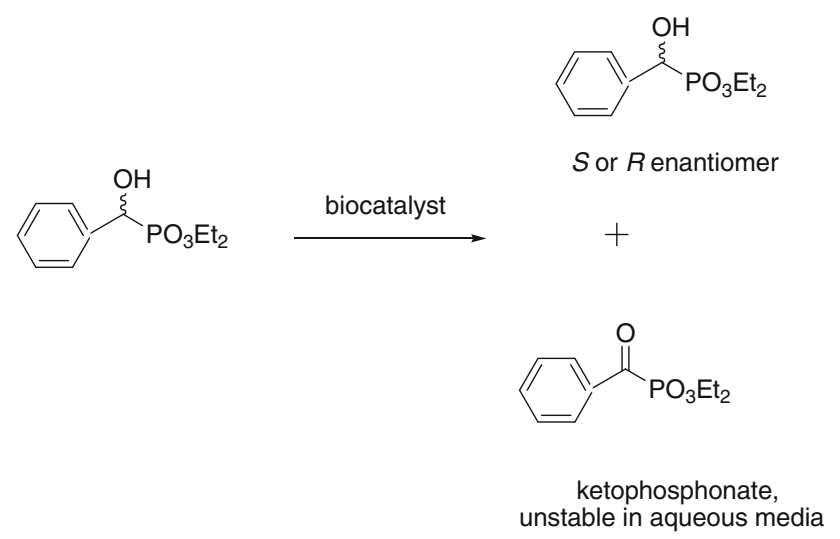

Fig. 1 Biocatalyzed synthesis of chiral diethyl 1-hydroxy-1phenylmethanephosphonate

Fungus was cultivated (with shaking $100 \mathrm{rpm}$, at room temperature) on the standard (DSMZ Medium 90) malt extract peptone liquid medium $(100 \mathrm{ml})$ in $250 \mathrm{ml}$ cultivation flask, until the mid-log growth phase (for 3 days), then the biomass was separated by centrifugation $(4,000 \mathrm{rpm} / 10 \mathrm{~min}$ ) — it allowed obtaining $8 \mathrm{~g}$ of the wet cells from every cultivation flask. After that, depending on the down stream, cells were used directly or preincubated for next $24 \mathrm{~h}$ under starvation conditions and then used as a biocatalyst. In both cases (with or without the starvation), also depending on the outcome, the cells were shaken with the addition of catalytic amount of cyclohexanone (the final concentration of the additive in the biotransformation flask was $1 \mathrm{mM}$ ). Details of the procedures are listed below.

\section{Biotransformation Media}

Aqueous medium or citrate buffer ( $\mathrm{pH} \mathrm{3,0.05} \mathrm{M)}$

\section{Biotransformation: General Procedure}

Biotransformation $(50 \mathrm{mM}$ of the substrate, $8 \mathrm{~g}$ wet cells after cultivation and centrifugation) was carried out in $50 \mathrm{ml}$ of biotransformation media for various times and at different temperatures with shaking at $250 \mathrm{rpm}$. Details of the protocols are listed below. Biocatalyst cells were removed by centrifugation $(4,000 \mathrm{rpm}, 10 \mathrm{~min})$, product was extracted from the supernatant with ethyl acetate, dried organic layer was evaporated, and final product was analyzed.

Protocol 1 fresh wet biomass, buffer, or aqueous medium, duration $1-7$ days, temp. $22^{\circ} \mathrm{C}$

Protocol $224 \mathrm{~h}$ starved biocatalyst cells, buffer, or aqueous medium, duration 1-7 days, temp. $22^{\circ} \mathrm{C}$

Protocol $324 \mathrm{~h}$ starved biocatalyst cells, buffer, or aqueous medium, duration 1-7 days temp. $30^{\circ} \mathrm{C}$
Protocol 4 fresh wet biomass, buffer, or aqueous medium, simultaneous addition of substrate and cyclohexanone $(1 \mathrm{mM})$, duration 3 days, temp. $22^{\circ} \mathrm{C}$

Protocol 5 fresh wet biomass, buffer, or aqueous medium, cyclohexanone $(1 \mathrm{mM})$ added $24 \mathrm{~h}$ before substrate, duration 1-5 days, temp. $22^{\circ} \mathrm{C}$

Protocol $624 \mathrm{~h}$ starved biocatalyst cells, buffer, or aqueous medium, simultaneous addition of substrate and cyclohexanone $(1 \mathrm{mM})$, duration 3 days, temp. $22^{\circ} \mathrm{C}$

Protocol $724 \mathrm{~h}$ starved biocatalyst cells, buffer, or aqueous medium, cyclohexanone $(1 \mathrm{mM})$ added $24 \mathrm{~h}$ before substrate, duration: 2 and 5 days, temp. $22^{\circ} \mathrm{C}$

NMR Assignments

NMR spectra were recorded on Bruker Avance DRX300 instrument operating at $300.13 \mathrm{MHz}$, measurements were made in $\mathrm{CDCl}_{3}(99.5$ at.\% D) at temperature of $300 \mathrm{~K}$.

Purity of the Product, Yield, and Enantiomeric Excess Determination: Optical Rotation Measurement

Product purity and the enantiomeric excess evaluation were done using NMR; ${ }^{31} \mathrm{P}$ spectra were recorded with the addition of equimolar amount of quinine, used as a chiral discriminator in the case of enantiomeric excess calculation. Absolute configuration was assayed by optical rotation measurement (in $\mathrm{CHCl}_{3}$ ), after the biotransformation, and the results were as follows: in the case of (A)-Fig. 2, $[\alpha]_{\mathrm{D}}^{20}=-38$ for $S$ enantiomer [16]; in the case (B)Fig. $2,[\alpha]_{\mathrm{D}}^{20}=+38$ and for $R$ enantiomer.

\section{Results and Discussion}

This work was inspired by our previous studies [3, 23], which employed different strains of fungi for the synthesis of P-chiral hydroxyphosphonate via enantioselective oxidation of hydroxyl functionality. Chemical procedures of the synthesis as well as prochiral keto phosphonates and racemic hydroxylphosphonates are cheap and efficient, therefore, these compounds can serve as convenient substrates for further reactions, including the biocatalyzed synthesis of the chiral products in a manner as simple and as economic as possible. Thus, in discussed case, the fungal strain Beauveria bassiana was used for the oxidative resolution of the racemic mixture of the model-diethyl 1-hydroxy-1-phenylmethanephosphonate. It turned out that 

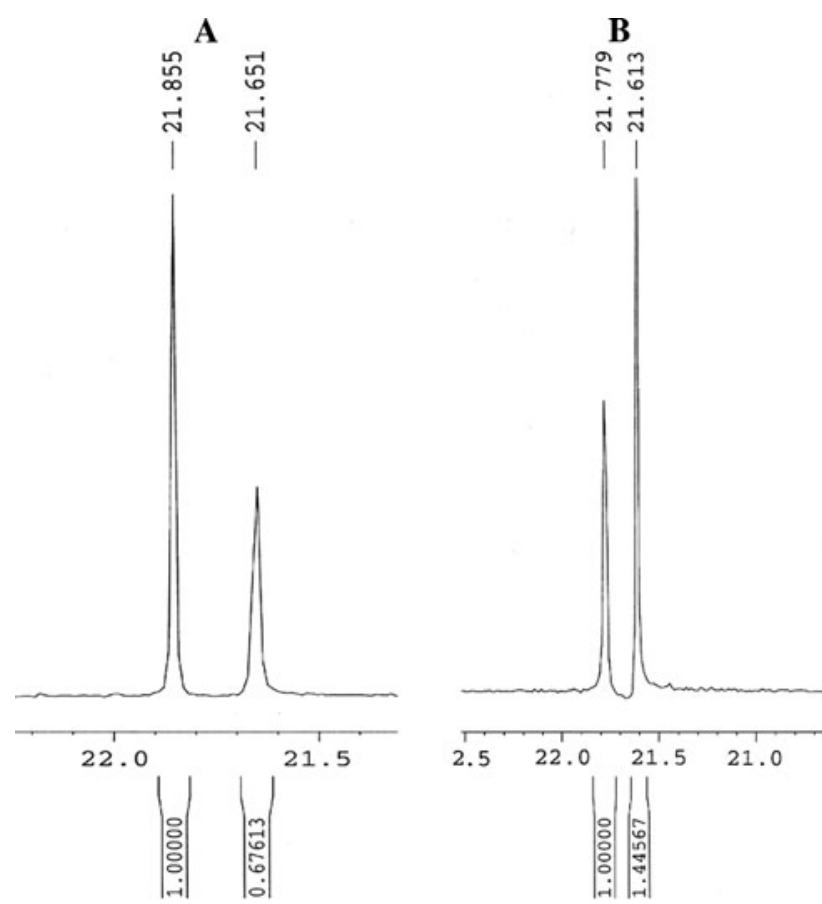

Fig. $2{ }^{31} \mathrm{P}$ NMR spectra of biotransformation products recorded with quinine. a without any additives, predominant enantiomer defined as $S$ isomer, b cyclohexanone as an additive, predominant enantiomer defined as $R$ one

this biocatalyst was active toward tested compound and, what is also important, the modification as well as the cells preincubation methods and biotransformation conditions, implied in the different stereoselectivity of the biooxidation. In order to obtain product of desired absolute configuration, different strategies were applied. First of all, the biocatalytic biomass was prepared with or without the starvation period followed the routine cells cultivation. It is obvious that the phosphonates are not physiological substrates for fungi, that is why, in some cases the starvation period is the solution, which forces the cells to utilize such compounds. It is necessary to stress that in discussed studies, the activity of Beauveria bassiana strain toward diethyl 1-hydroxy-1-phenylmethanephosphonate, was similar, no matter if the cells starved or not. However, there was other factor, significantly influencing the effectiveness and direction of the biotransformation. Thus, the addition of the catalytic amount of cyclohexanone (details are described in the "Materials and Methods" section) allowed controlling the enantioselectivity of the process, this crucial observation is clearly seen on the NMR spectra, which show the best results (Fig. 2a, b). The application of this additive implied in the enriching of the racemic mixture of the substrate in the enantiomer of $R$ absolute configuration after one day of biocatalysis. Bioconversion was carried out in aqueous media, at $22^{\circ} \mathrm{C}$ (Fig. 2b), while the

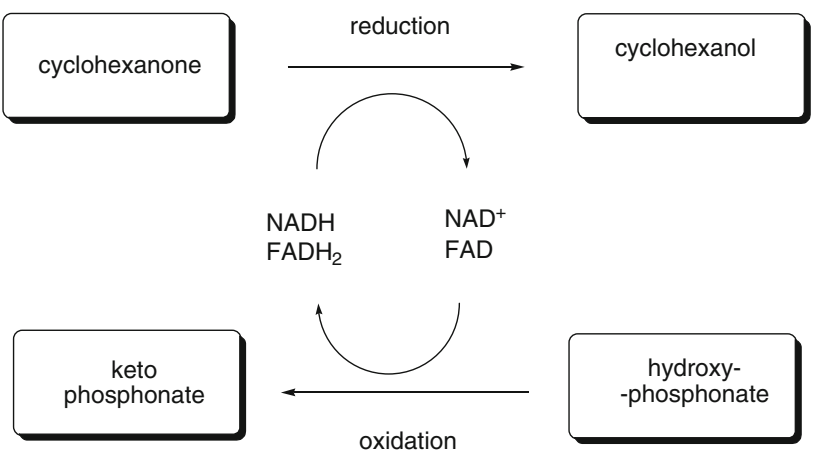

Fig. 3 Created cofactor regeneration system-cyclohexanone importance

experiment without any cells preincubation (Fig. 2a) allowed to increase the amount of the $S$ isomer after the bioconversion. The e.e values (about 20\%) are not satisfactory, but the procedure is worth to develop, because of their simplicity and possibility to obtain both the enantiomeric forms of the substrate.

The possible explanation of this phenomenon is that cyclohexanone and the biotransformation substratehydroxyphosphonate constitute the oxidases cofactor regeneration system. The catalytic amount of the additive moved the balance between the oxidized and reduced coenzyme forms, into oxidized ones, which were subsequently converted into reduced forms, accepting the electrons and protons from the biocatalysis substrate, which was simultaneously oxidized, what finally completed the reaction (Fig. 3).

Except from the mentioned above, variable cells preincubation procedures, Table 1 shows other efforts, which were undertaken to improve the effectiveness of the chiral hydroxyphosphonate synthesis. Thus, following conditions of the biooxidation were changed: temperature 22 or $30^{\circ} \mathrm{C}$; the reaction time, which varied from 1 to 7 days; biotransformation media-water or citrate buffer were applied. Unfortunately, these approaches were not effective, considering the yield and the enantiomeric excess of the products. However, in Table 1, there are some data, which undoubtedly focused the attention and required comments. Thus, the results of the biotransformation carried without the addition of the cyclohexanone are interesting, because the values of the enantiomeric excess changing with time and in some cases the inversion of the absolute configuration are observed. The possible explanation of this phenomenon is that enzymes inside the living cells are constitutive or inducible ones, and depending on the environmental conditions and on the metabolic state of the cells, particular enzymes are expressed. It implies in that the molar ratio of the enzymes of opposite enantiospecificities change with the reaction progress. Moreover, the protein heterogeneity (e.g. enantiospecificity) often 
Table 1 Results of the biooxidation of the substrate carried out under different conditions

\begin{tabular}{|c|c|c|c|c|c|c|c|c|c|c|c|c|c|c|c|}
\hline \multirow[t]{3}{*}{ Protocol $^{\mathrm{a}}$} & \multicolumn{15}{|c|}{ Biotransformation time (days) } \\
\hline & \multirow[t]{2}{*}{ Medium } & \multicolumn{2}{|l|}{1} & \multicolumn{2}{|l|}{2} & \multicolumn{2}{|l|}{3} & \multicolumn{2}{|l|}{4} & \multicolumn{2}{|l|}{5} & \multicolumn{2}{|l|}{6} & \multicolumn{2}{|l|}{7} \\
\hline & & $\%$ ee & $\mathrm{AC}$ & $\%$ ee & $\mathrm{AC}$ & $\%$ ee & $\mathrm{AC}$ & $\%$ ee & $\mathrm{AC}$ & $\%$ ee & $\mathrm{AC}$ & $\%$ ee & $\mathrm{AC}$ & $\%$ ee & $\mathrm{AC}$ \\
\hline \multirow[t]{2}{*}{1} & Water & 4.4 & $S$ & 8.4 & $S$ & 5.1 & $S$ & 4.2 & $R$ & 20.4 & $S$ & 4.7 & $S$ & 11.6 & $S$ \\
\hline & Buffer & 10.7 & $S$ & 11.2 & $R$ & 10.4 & $R$ & 3.6 & $R$ & 1.7 & $R$ & 6.8 & $R$ & 4.8 & $S$ \\
\hline \multirow[t]{2}{*}{2} & Water & 5.2 & $S$ & 5.1 & $S$ & 11.5 & $R$ & 12.0 & $S$ & 13.0 & $R$ & 1.7 & $R$ & 10.5 & $R$ \\
\hline & Buffer & 2.7 & $R$ & 4.8 & $S$ & 10.2 & $R$ & 8.5 & $R$ & 1.0 & $R$ & 3.0 & $S$ & 1.2 & $S$ \\
\hline \multirow[t]{2}{*}{3} & Water & 1.5 & $S$ & 1.8 & $R$ & 1.4 & $R$ & 6.0 & $R$ & 0.0 & - & 6.6 & $R$ & 2.7 & $S$ \\
\hline & Buffer & 10.7 & $R$ & 6.3 & $R$ & 0.0 & - & 4.9 & $S$ & 2.6 & $S$ & 0.0 & - & 14.8 & $R$ \\
\hline \multirow[t]{2}{*}{4} & Water & & & & & 6.3 & $S$ & & & & & & & & \\
\hline & Buffer & & & & & 5.4 & $S$ & & & & & & & & \\
\hline \multirow[t]{2}{*}{5} & Water & 17.2 & $\boldsymbol{R}$ & 0 & - & 8.3 & $R$ & 7.3 & $R$ & 1.5 & $S$ & & & & \\
\hline & Buffer & 2.6 & $R$ & 7.3 & $S$ & 2.7 & $S$ & 16.3 & $S$ & 8.7 & $S$ & & & & \\
\hline \multirow[t]{2}{*}{6} & Water & & & & & 12.6 & $S$ & & & & & & & & \\
\hline & Buffer & & & & & 0 & - & & & & & & & & \\
\hline \multirow[t]{2}{*}{7} & Water & & & 13.7 & $R$ & & & & & 2.3 & $S$ & & & & \\
\hline & Buffer & & & 2.3 & $S$ & & & & & 1.7 & $S$ & & & & \\
\hline
\end{tabular}

Bold values represent the best results

a Protocols are described in "Materials and Methods" section

$e e$ enantiomeric excess, $A C$ absolute configurations

results from the coexistence of interconvertible isomeric forms of the monomeric enzyme, which also can be an explanation of the presented in Table 1 data. The results of the bioconversion are interesting as well, when the reaction is carried out at the cyclohexanone presence. It is clearly seen that the added compound affects the activity of the enzymes involved in the oxidation of the phosphonic substrate. After the simultaneous introduction of the mentioned chemicals, the lack of the reaction is observed or the results are very poor, it seems that these compounds are competitive to each other and the cyclohexanone is preferred one. In turn of the sequence addition (substrate followed the cyclohexanone), the enantiospecificity differs depending also on the biotransformation media. Thus in water, at early stage of the process, the oxidase of the $S$ preference is active, so the predominant, unreacted product is of $R$ absolute configuration. This reaction state is changing with the bioconversion progress, the enzyme of opposite specificity becomes a prevalent one. This phenomenon probably resulted from the reasons already discussed above. Otherwise, when the biocatalysis is carried out in buffer the lack of the reaction is observed or the enzyme of $R$ enantiospecificity is in the ascendance (predominant product is of $S$ absolute configuration). It seems that this results imply largely from the sensitivity of the oxygenase of opposite specificity to the presence of the cations or/and anions, which formed the citric buffer. Assuming, presented studies are another valuable report of scope and limitations of the application of the biocatalysts.
Acknowledgments This work was financed from Project "Biotransformations for pharmaceutical and cosmetics industry" No.POIG.01.03.01-00-158/09-01 part-financed by the European Union within the European Regional Development Fund for the Innovative Economy.

Open Access This article is distributed under the terms of the Creative Commons Attribution Noncommercial License which permits any noncommercial use, distribution, and reproduction in any medium, provided the original author(s) and source are credited.

\section{References}

1. Caner H, Groner E, Levy L, Agranat I (2004) Trends in the development of chiral drugs. Drug Discov Today 9:105-110

2. Kafarski P, Lejczak B (2001) Aminophosphonic acids of potential medical importance. Curr Med Chem Anti Cancer Agents 1301-1312

3. Klimek-Ochab M, Żymańczyk-Duda E, Brzezińska-Rodak M, Majewska P, Lejczak B (2008) Effective fungal catalyzed synthesis of P-chiral organophosphorus compounds. Tetrahedron Asymmetry 19:450-453

4. Kolodiazhnyi OI (2005) Asymmetric synthesis of hydroxyphosphonates. Tetrahedron Asymmetry 16:3295-3340

5. Kolodiazhnyi OI (2006) Chiral hydroxy phosphonates: synthesis, configuration and biological properties. Russ Chem Rev 75: 227-253

6. Lejczak B, Kafarski P (2009) Biological activity of aminophosphonic acids and their short peptides. Top Heterocycl Chem 20:31-63

7. Leuenberger HGW (1990) Biotransformation-a useful tool in organic chemistry. Pure Appl Chem 62:753-768 
8. Li YF, Hammerschmidt F (1993) Enzymes in organic chemistry, Part 1: enantioselective hydrolysis of a-(acyloxy)phosphonates by esterolytic enzymes. Tetrahedron Asymmetry 4:109-120

9. Liese A, Filho MV (1999) Production of fine chemicals using biocatalysis. Curr Opin Biotechnol 10:595-603

10. Majewska P, Kafarski P, Lejczak B (2005) Lipase-catalysed resolution of 1-hydroxyethane-P-phenylphosphinates. Pol J Chem 79:561-566

11. Majewska P, Kafarski P, Lejczak B, Bryndal I, Lis T (2006) An approach the synthesis and assignment of the absolute configuration of all enantiomers of ethyl hydroxy(phenyl)methane $(\mathrm{P}-$ phenyl)phosphinate. Tetrahedron Asymmetry 17:2697-2701

12. Mikołajczyk M, Balczewski P (2003) Phosphonate chemistry and reagents in the synthesis of biologically active and natural products. Top Curr Chem 223:162-214

13. Pollard DJ, Woodley JM (2007) Biocatalysis for pharmaceutical intermediates: the future is now. Trends Biotechnol 25:66-73

14. Schmidt A, Dordick JS, Hauer B, Kiener A, Wubbolts M, Withold B (2001) Biocatalysis biochemical fundamentals and applications. Nature 409:258-268

15. Shioji K, Tashiro A, Shibata S, Okuma K (2003) Synthesis of bifunctional P-chiral hydroxy phosphinates; lipase-catalyzed stereoselective acylation of ethyl (1-hydroxyalkyl)phenylphosphinates. Tetrahedron Lett 44:1103-1105

16. Skropeta D, Schmidt R, Richard (2003) Chiral, non-racemic ahydroxyphosphonates and phosphonic acids via stereoselective hydroxylation of diallyl benzylphosphonates. Tetrahedron Asymmetry 14:265-274
17. Texier-Boulet F, Foucand A (1982) A convenient synthesis of dialkyl 1-hydroxyalkanephosphonates using potassium or caesium fluoride without solvent. Synthesis 2:165-166

18. Timmis KN, Pieper DH (1999) Bacteria designed for bioremediation. Tibtech 17:201-204

19. Yamagishi T, Miyame T, Yokomatsu T, Shibuya S (2004) Lipase-catalyzed kinetic resolution of $\alpha$-hydroxy-H-phosphinates. Tetrahedron Lett 45:6713-6716

20. Yoshida T, Nagasawa TJ (2000) Enzymatic functionalization of aromatic $N$-heterocycles: hydroxylation and carboxylation. Biosci Bioeng 89:111-118

21. Zhang Y, Li JF, Yuan CY (2003) Enzymatic synthesis of optically active trifluoromethylated 1- and 2-hydroxyalkanephosphonates. Tetrahedron 59:473-479

22. Żymańczyk-Duda E, Brzezińska-Rodak M, Lejczak B (2004) Stereochemical control of asymmetric hydrogen transfer employing five different kinds of fungi in anhydrous hexane. Enzym Microb Technol 34:578-582

23. Żymańczyk-Duda E, Lejczak B, Kafarski P, Grimaud J, Fischer P (1995) Enantioselective reduction of diethyl 2-oxoalkylphosphonates by baker's yeast. Tetrahedron 51:11809-11814

24. Żymańczyk-Duda E, Klimek-Ochab M, Kafarski P, Lejczak B (2005) Stereochemical control of biocatalytic asymmetric reduction of diethyl 2-oxopropylphosphonate employing yeasts. J Organomet Chem 690:2593-2596 